University of South Carolina

Scholar Commons

6-1992

\title{
An Attributional Analysis of Resistance to Group Pressure Regarding Illicit Drug and Alcohol Consumption
}

\author{
Randall L. Rose \\ University of South Carolina - Columbia, roser@moore.sc.edu \\ William O. Bearden \\ University of South Carolina - Columbia, bbearden@moore.sc.edu \\ Jesse E. Teel
}

Follow this and additional works at: https://scholarcommons.sc.edu/mark_facpub

Part of the Marketing Commons

\footnotetext{
Publication Info

Journal of Consumer Research, Volume 19, Issue 1, 1992, pages 1-13.

http://jcr.wisc.edu/

(c) 1992 by Journal of Consumer Research, Inc.
}

This Article is brought to you by the Marketing Department at Scholar Commons. It has been accepted for inclusion in Faculty Publications by an authorized administrator of Scholar Commons. For more information, please contact digres@mailbox.sc.edu. 


\title{
An Attributional Analysis of Resistance to Group Pressure regarding Illicit Drug and Alcohol Consumption
}

\author{
RANDALL L. ROSE \\ WILLIAM O. BEARDEN \\ JESSE E. TEEL*
}

\begin{abstract}
This article investigates the role of attributional thinking in generating resistance to pressures toward conformity in the illicit consumption of drugs and alcohol. The results of four studies regarding how conformity influences illicit drug and alcohol consumption among high school and college students are reported. In study 1 more than two-thirds of the respondents reported concern for the implications of their own dissent or compliance regarding the reactions of their peers. Study 2 demonstrated a significant relationship between high school students' attributional thinking concerning a peer group's illicit beer consumption and conformity, expressed as intentions to drink the beer. In study 3 , in-depth interviews with high school students provided insight into the realism of the conformity scenarios used in the research and the types of conformity pressures experienced by young people. In study 4 , locus of causality, an abstract attributional dimension, and several specific attributions were shown to be significantly associated with conformity in the consumption of marijuana.
\end{abstract}

\begin{abstract}
A ccording to a recent Gallop poll, drug and alcohol abuse has become the issue of greatest concern to many Americans. The influence of other persons, individually and in groups, is frequently used to describe the decision to use illicit drugs and alcohol, especially among adolescents and young adults (e.g., Halebsky 1987; Marcos, Bahr, and Johnson 1986; Winfree 1985). President George Bush, in his "National Strategy on Drug Abuse," a nationally televised address on September 5, 1989, blamed peer pressure for much of the nation's drug problem and argued that peer pressure could also affect a reduction in drug abuse. Unfortunately, little research regarding the consumption of either traditional products and services or illicit drugs and alcohol has been directed toward understanding the mediating processes through which pressures to conform are ultimately manifested in conforming behaviors.

Interpersonal influence from a cognitive perspective stems not so much from a passive submission to group

${ }^{*}$ Randall L. Rose is assistant professor of marketing, William $\mathrm{O}$. Bearden is professor of marketing, and Jesse E. Teel is professor of marketing, all in the College of Business Administration, University of South Carolina, Columbia, SC 29208. The authors would like to thank Bob Burnkrant, Joel Cohen, Valerie Folkes, Peter Reingen, Terry Shimp, and the three reviewers for their insights and encouragement.
\end{abstract}

norms but often from complex attributional and perceptual processes that the individual being influenced engages in to understand the causes of the behaviors and opinions of the influencing agents or referents (see Folkes 1988; Mizerski, Golden, and Kernan 1979). In the consumer-behavior literature, Calder and Burnkrant (1977) first proposed an attributional model of consumer interpersonal influences. This model, while never tested in its entirety, proposes that conformity in the purchase of products and services is mediated by the consumer's attributions regarding the likely reactions of referent others to his/her product choices. Similarly, conformity to peers is often considered to be one of the hallmarks of adolescent and young adult behavior (Brown, Clasen, and Eicher 1986). However, it is somewhat surprising that little effort has been made to ascertain the nature of adolescents' cognitive responses to peer pressures. We believe that a cognitive perspective, focusing primarily on encouraging young people to seek explanations (or certain types of explanations) for a peer group's illicit behavior, offers considerable promise as a means of reducing conformity in the consumption of drugs and alcohol (see Ross, Bierbrauer, and Hoffman 1976).

Therefore, we investigated cognitive responses to conformity pressure in the domain of drug and alcohol abuse among young people, particularly the attribu- 
tional nature of their thinking and the implications of attributional thinking for conformity. As background to a discussion of the role of attributional processing in conformity, we present a brief review of the literature concerning conformity and substance abuse.

\section{CONFORMITY AND SUBSTANCE ABUSE}

It appears that the individual's need for affiliation with his or her peers is manifested by conformity to group norms and that the group itself is strengthened when members exert conformity pressures on one another (Brown et al. 1986). While the strong influence of peers on drug and alcohol use has been documented, little is known about the thought processes that precede decisions to conform to group pressures. Most research has been restricted to the study of peers' drug and alcohol use based on its role either as a behavior model or as a source of substance availability (Stein, Newcomb, and Bentler 1987). Again, research regarding the cognitive antecedents and thought processes that individuals engage in when confronted with a conformity decision seems warranted.

The literature dealing with drug abuse among both adolescents and adults is extensive. And, a number of studies have examined various aspects of the relationships among peer-related factors, conformity to peer pressures, and illicit drug and alcohol consumption. Consequently, a complete review is impossible here. Further, peer influences represent only one of many types of influences affecting drug and alcohol consumption among young people (e.g., family, personality, socioeconomic status). However, some recent results are suggestive of our basic premise that attributions and other thoughts made prior to conformity or dissent decisions are important and worthy of direct investigation. For example, Wolfe, Lennox, and Cutler (1986) demonstrated that self-reported drug use was positively correlated with the individual's concern for appropriateness-a measure of self-presentation style associated with social anxiety, avoiding disapproval, and conformity. Clearly, social anxiety and disapproval fears involve attributional thoughts about the potential reactions of others. Likewise, the potential young user of drugs typically has peers who are drug users, and the formation of friendship circles with such individuals appears to be a strong causal influence in drug abuse (e.g., Huba and Bentler 1980; Jessor and Jessor 1977; Kandel, Kessler, and Margulies 1978). Further, research has shown that, while varying across groups, peer influences may either enhance or detract from parental effects (Brook, Whiteman, and Gordon 1983) and that personality, peer, and family factors can have independent effects on drug-use behavior. In conclusion, Kaplan, Martin, and Robbins (1985, p. 208) provide an excellent summary: "The individual's disposition to use illicit drugs is generally felt to be congruent with the values shared by members of the person's membership/ reference groups. In situations where the illicit use of drugs is compatible with group values, the person will be disposed toward the use of these drugs, particularly under conditions where experiences in the group are characterized by conformity to and acceptance by group members."

In the next section, consumer social influence processes in general and with respect to the illicit consumption of drugs and alcohol are interpreted from an attributional perspective. The results of four studies designed to provide evidence regarding the nature of the cognitive responses underlying social influences are then presented. Last, study implications, limitations, and several suggestions for future research are discussed.

\section{ATTRIBUTION PROCESSES IN CONFORMITY}

Before beginning our discussion of the role attribution processes play in conformity, it is important to explicate our use of the term "attribution" and what we mean by attributional thoughts in the context of this research. Typically in consumer research, the term "attribution" is used synonymously with "causal attribution" (cf. Folkes 1984; Heider 1958). In other words, attributions are considered to be answers to "why" questions, such as "Why did the product fail?" Our use of the term attribution is less narrow in the sense that we do not restrict attributional thinking to causal reasoning. In this research, attribution assumes its traditional meaning - the drawing of a conclusion from reasoning based on what is known or assumed. In this research, an attribution is any inferential belief that an individual draws from reasoning based on evidence or assumptions about himself or herself (i.e., self-attributions) or the behavior, thoughts, feelings, or dispositions of a peer group. Our use of the term attribution includes, but is not limited to, causal attribution. This usage is consistent with the attributional conformity model of Ross et al. (1976) described below and the attributional model of consumer conformity developed by Calder and Burnkrant (1977).

\section{Attribution Problems in Conformity and Dissent}

Ross et al. (1976) have demonstrated that conformity pressures operative in a setting similar to Asch's (1951) are, in fact, very powerful. Participants in the Asch (1951) experiments are thrown into an "attribution crisis" by the seemingly irrational judgments of the confederates in an objective, perceptual task (e.g., judgments of line lengths; Ross et al. 1976, p. 149). Assuming that subjects are unaware of the deception, each participant is left with several perplexing questions 
FIGURE 1

AN ATTRIBUTION MODEL OF CONFORMITY

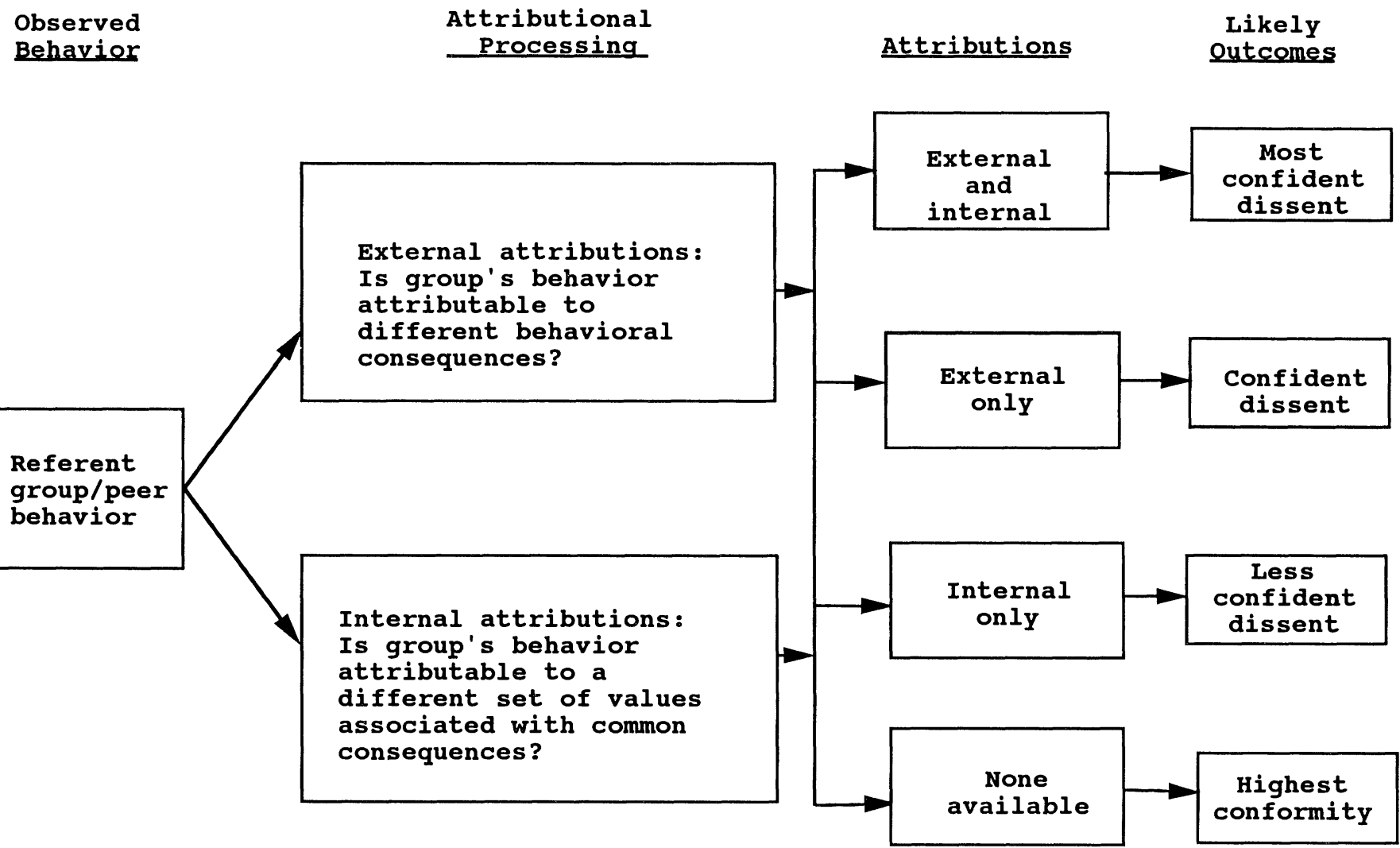

to answer before deciding whether to conform to the group's judgment. The key from an attribution perspective is the nature of the attribution(s) made by the subject to account for the unanimous, but incorrect, judgments made by the confederates. A subject's thinking might proceed in the following manner: "How could the other group members make such an obviously incorrect judgment? They must surely feel as confident of the correctness of their choice as I do that it is incorrect. Therefore, if I disagree, I'll be challenging their competence. On the other hand, if I agree, I'll be making what is, to me, an obviously incorrect choice." To the extent that the subject is unable to construct a plausible alternative explanation for the group's behavior, this kind of setting undermines the very foundation of each participant's conception of objective reality (Ross et al. 1976). Similar questions may arise when adolescents are faced with conformity pressures relating to drug or alcohol consumption.

The attribution problems faced by potential dissenters may be categorized into three basic types of questions (Ross et al. 1976): (1) Why are my peers expressing these judgments or performing these behaviors? (2)
What would my dissent imply to the group about me and my perception of the group? and (3) What would my dissent imply to me about myself? An answer to the first question requires the individual to find a plausible explanation for the group's judgment or behavior. The second question may be even more difficult because it requires speculation about the group's likely responses to the individual's own judgment and behavior (dissent). The answer to the third question requires a process of self-perception. The research reported in this article addresses, at least in part, each of these three questions.

\section{Resolving the Attribution Dilemma}

One process by which individuals resolve the conformity dilemma noted above is depicted in Figure 1. In this framework, attribution processes are triggered by exposure to the judgments or behavior of an individual referent or group. The potential dissenter first searches for explanations for the difference between the group's judgment and his/her own. The success or fail- 
ure of these efforts to identify plausible explanations for the difference of opinion between the group and the individual determines, in part, the individual's decision to conform or to dissent. Explanations for the group's behavior may be either internal or external. In other words, a group of teenagers may be drinking beer because they feel pressure to drink from an older referent group present at a party (i.e., an external explanation for their behavior), or the teenagers could be drinking because they like getting "high" (i.e., an internal explanation for their behavior). Thus, external explanations for behavior are those that place the locus of causality for the observed behavior outside the actors (e.g., situational factors such as group pressure or coercion). Internal explanations for behavior are those that attribute the locus of causality to something inside the actors (e.g., dispositions, values, attitudes; Miller, Smith, and Uleman 1981).

Attributing a group's behavior to external causes provides an important mechanism for reducing perceived conformity pressures, because such attributions may be used to explain the observed differences in behavior or judgment between the group and the potential dissenter (Ross et al. 1976). For example, consider the case of a 19-year-old whose best friends are old enough to buy alcoholic beverages (i.e., at least 21 years of age). She goes out to eat with this group of close friends, all of whom order a drink before dinner. If she attributes the behavior of her friends to the fact that they are of legal drinking age and therefore not subject to penalties in this situation, then her decision not to conform would be bolstered. Similarly, she knows that her friends will probably attribute her decision not to drink to her age and to the potential penalties for public underage drinking rather than to a desire to violate group norms. Therefore, because of the availability of external explanations for the group's behavior, her dissent carries little risk.

This type of attribution process is, perhaps, typical of many consumption settings involving pressures toward conformity. Note that in this process the potential dissenter's evaluation of the desirability of being old enough to drink as a reason for drinking is not considered. The ready availability of plausible external attributions accounting for other group members' behavior reduces the pressures toward conformity experienced by a potential dissenter within the group, regardless of the evaluation of the favorability of that explanation.

Unfortunately, explanations for a group's behavior often may not be readily available. If, for example, members of the group described above were less than 21 years of age, it would be more difficult for the potential dissenter to attribute the group members' decision to order drinks to external, situational causes. With no ready external explanation, the individual is left with the more speculative option of attributing the group's behavior to internal causes (e.g., differences in dispositions between the individual and the other group members). Thus, the potential dissenter may attribute the group's behavior to different values or weights assigned to the possible consequences of that behavior. For example, to make an internal attribution that would support dissent, the individual must assume that the other group members care less about being arrested for underage drinking or about parental disapproval or evaluate certain potential social rewards, such as group approval, more favorably than she does. However, to the extent that the individual believes that members of her group are likely to possess values similar to her own, her confidence in these internal attributions is likely to decline. Although she may still explain away the group's behavior by saying to herself, "They're just different," her dissent may be more tenuous and more susceptible to change under future conformity pressures than would be the case if external attributions were readily available.

In summary, Ross et al.'s (1976) model suggests that attributional processing is likely to occur in conformity settings and that, when at least one plausible explanation for the group's behavior is available, dissent is enhanced relative to a situation in which no plausible explanation for the group's behavior is found. That is, conformity should be most common and dissent most painful when neither external nor internal attributions are available to account for the group's behavior. These expectations are stated formally below. Further, dissent is bolstered most strongly by the availability of external explanations for a peer group's illicit behavior.

H1: Consumers engage in spontaneous attribution processes when exposed to pressures toward conformity in the consumption of drugs and alcohol.

H2: Conformity is lower among individuals who are able to explain a salient group's behavior than it is among individuals who cannot account for the group's behavior.

H3: Conformity is lower among individuals who make external attributions to account for a referent group's behavior than it is for those who make internal attributions.

\section{STUDIES 1 AND 2}

The first two studies were designed to investigate the extent to which inferences about the behavior and opinions of others are made in conformity situations and about the likely reactions of others to the conformity or dissent of the target individual. This beginning phase of the research was intended to be exploratory and descriptive of cognitive responses to drug- and alcohol-consumption situations. In study 2 , an attempt was also made to assess the degree of association between attributional processing and conformity. 
EXHIBIT 1

THOUGHT CATEGORIES AND EXAMPLES

\begin{tabular}{|c|c|}
\hline Category & Example \\
\hline $\begin{array}{l}\text { 1. Supportive arguments: statements of affirmation/agreement with the group's } \\
\text { position; generation of supportive facts and evidence }\end{array}$ & "If my friends are doing it, it must be all right." \\
\hline $\begin{array}{l}\text { 2. Counterarguments: statements of disagreement/attacks on group's position; } \\
\text { generation of undermining facts and evidence }\end{array}$ & $\begin{array}{l}\text { "Smoking is against the law." "People can ruin their } \\
\text { lives this way." }\end{array}$ \\
\hline 3. Situational and dispositional attributions: explanations for the group's behavior & $\begin{array}{l}\text { "I guess they're doing this because they know that they } \\
\text { won't get caught." "They just want to get high." }\end{array}$ \\
\hline $\begin{array}{l}\text { 4. Concern for the attributions of others: questions or comments about the likely } \\
\text { attributions of the group or others concerning the respondent's own behavior }\end{array}$ & "What will they think of me if I don't?" \\
\hline 5. Attribution questions: questions reflecting a search for causal explanations & $\begin{array}{l}\text { "Why do my friends think differently about smoking pot } \\
\text { than I do?" }\end{array}$ \\
\hline $\begin{array}{l}\text { 6. Self-attributions: questions concerning the implications of the respondent's } \\
\text { behavior for his or her self-concept }\end{array}$ & "What would I be if I went along?" \\
\hline 7. Nonattributional questions & "Would I get caught?" \\
\hline 8. Issue avoidance & "I wouldn't go to a party like that." \\
\hline 9. Irrelevant, nonclassifiable & "This is a waste of time." \\
\hline
\end{tabular}

\section{Method}

Seventy-two undergraduate university students and 81 high school students participated in studies 1 and 2, respectively. In study 1 , the subjects were given one of two written descriptions, one involving the use of marijuana at a party and the other involving the consumption of alcohol by those who are underage. In study 2, high school students responded to the underage-drinking scenario (differences between the contexts are described below). In each scenario, the subjects encountered close friends already engaged in the illicit behavior. Subjects were asked to consider the situation carefully, to place themselves in the role of the student described in the scenario, and to imagine that they and their own friends were involved. ${ }^{1}$

The subjects were then given a questionnaire that required them to list any thoughts that they had regarding any aspect of the conformity situation. The instructions were purposely nondirective to avoid requiring the respondents to engage in any particular thought pattern. These methods are consistent with the recommendations and procedures of Weiner (1985) and Wong and Weiner (1981) concerning the use of freeelicitation attribution measures. After listing their thoughts, respondents in study 1 were asked to rank

\footnotetext{
'Debriefing remarks revealed that only the beer-consumption scenario for the high school students (study 2) involved the presence of any questioning of the context or procedures. It is sad to report that several respondents (5-6) indicated in study 2 that the research could have been conducted using younger, middle-school students. An attempt was also made to influence the prevalence of attributional thoughts during respondents' exposure to the alcohol scenario in study 2 by instructing some respondents to think about the reasons for the group's behavior. These instructions had no effect on conformity or on the prevalence of attributional thinking and, therefore, responses were pooled for key analyses.
}

order these thoughts according to importance to the conformity decision. In study 2 only, intentions to drink beer were measured on an 11-point scale anchored by "certainly would drink the beer" (11) and "there is no chance I would drink the beer" (1). This measure required subjects to place themselves in the situation described in the scenario before responding.

\section{Results}

The open-ended elicitation tasks resulted in 388 separate thoughts in study 1 and 264 thoughts in study 2 . These data were coded by two judges who were familiar with the schema used to categorize the elicited thoughts but who were not knowledgeable about the objectives of this research. As shown in Exhibit 1, the thoughts were coded into one of nine categories. The coding scheme drew heavily from three sources: (1) traditional cognitive-response coding procedures (Wright 1975), (2) attributional theory emphasizing external and internal causes of behavior (Heider 1958), and (3) Ross et al.'s (1976) description of conformity-related attributional processing. The categories included both support arguments and counterarguments in addition to a series of codes reflecting statements and questions regarding explanations about the group's behavior (e.g., internal and external attributions) and self-attributions. In total, four of the categories (i.e., categories 3-6) were considered to be attributional in content. Initially, the judges agreed on 84 percent of the thoughts coded in study 1 . After discussion, another 10 percent of the thoughts were successfully categorized. Only 6.2 percent of the responses were finally deemed irrelevant or uncodable. These were more reflective of truly irrelevant observations or statements as opposed to cases that simply did not fit another category. The initial agreement rate 
TABLE 1

THOUGHT-ELICITATION RESULTS

\begin{tabular}{|c|c|c|c|c|c|c|}
\hline \multirow[b]{3}{*}{ Thought categories } & \multicolumn{4}{|c|}{ Study 1} & \multirow{2}{*}{\multicolumn{2}{|c|}{ Study 2}} \\
\hline & \multirow{2}{*}{$\begin{array}{l}\text { No. of } \\
\text { respondents } \\
\text { mentioning }\end{array}$} & \multirow[b]{2}{*}{$\begin{array}{l}\text { No. of } \\
\text { mentions }\end{array}$} & \multirow[b]{2}{*}{$\begin{array}{l}\text { Percentage of } \\
\text { total }\end{array}$} & \multirow{2}{*}{$\begin{array}{c}\text { Ranked } \\
\text { most } \\
\text { important }\end{array}$} & & \\
\hline & & & & & $\begin{array}{l}\text { No. of } \\
\text { mentions }\end{array}$ & $\begin{array}{c}\text { Percentage of } \\
\text { total }\end{array}$ \\
\hline 1. Support arguments & 25 & 45 & 11.5 & 3 & 45 & 17.0 \\
\hline 2. Counterarguments & 64 & 124 & 32.0 & 38 & 32 & 12.1 \\
\hline 3. Situational and dispositional attributions & 9 & 10 & 2.6 & 1 & 12 & 4.5 \\
\hline 4. Concern for attributions of others & 54 & 81 & 20.9 & 13 & 66 & 25.0 \\
\hline 5. Attributional questions & 14 & 20 & 5.2 & 2 & 18 & 6.8 \\
\hline 6. Self-attributions & 5 & 5 & 1.3 & 2 & 14 & 5.3 \\
\hline 7. Nonattributional questions & 31 & 54 & 13.9 & 9 & 65 & 24.6 \\
\hline 8. Issue avoidance & 19 & 25 & 6.4 & $<$ & 4 & 1.5 \\
\hline 9. Irrelevant, nonclassifiable & 16 & 24 & 6.2 & 2 & 8 & 3.0 \\
\hline Total & $\ldots$ & 388 & 100.0 & $\ldots$ & 264 & 100.0 \\
\hline
\end{tabular}

was 75 percent in study 2 , and only 3 percent of the thoughts were ultimately considered unclassifiable.

The frequency distribution of the responses across the nine thought categories is presented in Table 1. As shown, the most frequently elicited thoughts in both studies involved counterarguments (e.g., statements of disagreement with the group's position or undermining facts or evidence). However, a number of attributionrelated responses (i.e., categories 3-6) did occur in both samples, as predicted by Hypothesis 1 and consistent with the results of Ross et al. (1976). The most frequently mentioned of these attributional thoughts (category 4) reflected concerns regarding the attributions of others about the behavior of the subject (e.g., "What will they think of me if . . . ?"), a result that supports the predicted role of attributional sensitivity as a determinant of consumer conformity (Calder and Burnkrant 1977). It is interesting that 76 percent of the subjects in study 1 and 64 percent of the subjects in study 2 recorded at least one attributional thought. In study 1 , respondents ranked either counterarguments (38 mentions) or category 4 thoughts concerning the likely reactions of group members (13 mentions) as most important in conformity decisions.

Consistent with Ross et al. (1976), the presence of attributional thinking was expected to bolster dissent. In study 2 , this proposition was tested by splitting the sample into two groups made up of those respondents who either did (code $=1, n=52$ ) or did not (code $=0, n=29$ ) report at least one thought that was classified as attributional and assigned to category 3, 4, 5, or 6 . Analysis of variance with intentions as the criterion and the dichotomized attributional thought variable as the predictor revealed the expected effect. Those respondents who reported at least one attributional thought exhibited lower intentions to drink beer $(\bar{X}$ $=5.33$ ) than those who did not engage in attributional processing $(\bar{X}=7.90, F(1,79)=10.20, p<.01)$. Con- sistent with this finding, the correlation between the attribution dummy-variable and intentions was significant and negative $(r=-.34, p<.01){ }^{2}$

\section{Discussion}

Study 1's primary contribution lies in its description of the nature of the cognitive responses generated by exposure to the peer-pressure scenarios. Although arguments counter to the group members' behavior were most prominent, especially for the drug scenario, most of the subjects also reported thoughts indicative of attributional processing, as expected. Further, support was obtained for the attributional models of conformity proposed by Ross et al. (1976) and Calder and Burnkrant (1977). In particular, more than two-thirds of the subjects reported concern for the implications of their own behavior (i.e., conformity or dissent) for the attributions and other reactions of their peers. The attributional content of thoughts reported differed little across the two samples. However, it is worth noting that considerably fewer counterarguments and more support arguments were reported in response to the beer scenario, a result that probably reflects the students' perception that alcohol consumption is more socially acceptable (even for high school students). Additional evidence concerning how important attributional processing is to dissent in such situations was provided in

\footnotetext{
${ }^{2} \mathrm{~A}$ reviewer questioned our interpretation of category 4 thoughts ("concern for the attributions of others") as attributional in nature, preferring instead to focus on causal attributions. Therefore, we ran the same analysis with the "concern" thoughts deleted from the attributional dummy variable. The conformity means differed, as before, in the expected direction (attributional thinking present: $\bar{X}=5.13$; attributional thinking absent: $\bar{X}=6.98 ; p<.05$ ). This result indicates that the presence of attributional thinking is inversely related to conformity, even when attributional thinking is restricted to causal reasoning.
} 
study 2 , in which differences in conformity were found between those individuals who reported at least one attributional thought and those who did not.

Both studies 1 and 2 relied on role-playing scenarios that were developed through pretesting among college students. Although the use of such scenarios is appropriate given the sensitive nature of the research topic, any conclusions drawn from such studies must be made with caution. A reasonable question to ask is whether the scenarios captured the reality of peer pressures regarding drug and alcohol consumption among young people. Evidence regarding the nature of pressures to use drugs and alcohol in the lives of high school students and the nature of students' responses to those pressures is reported in study 3 .

\section{STUDY 3}

Role-playing methods and private measures are limited in their ability to re-create the richness and poignancy of real settings in which young people are exposed to peer pressures. Although the ubiquitous nature of such situations in everyday life may have facilitated respondents' ability to assume the roles required of them, additional insights regarding the realism of the consumption scenarios was obtained through a series of depth interviews with young people. The purpose of study 3 was to provide a richer description of the conformity pressures actually faced by young people, to examine the prevalence of the cognitive responses and attributional processing described in this research, and to provide support for the realism of the role-playing scenarios. $^{3}$

\section{Method}

We returned to the high school from which the student sample in study 2 was drawn after obtaining parental permissions from a group of 18 students who volunteered to be interviewed individually and anonymously. Two students were interviewed initially in a pretest of the depth-interview procedure, and their comments were used to improve the questions that were asked in the remaining interviews. An additional student was dropped because she had never been in a situation in which others were consuming drugs or alcohol. Of the remaining 15 students, all were third- and fourth-year high school students, and 11 were female. The semistructured interviews lasted 15-20 minutes and were conducted privately in a conference room at the high school.

\section{Results}

Six of the respondents indicated that they had been present when marijuana was being used, and all 15 had

\footnotetext{
${ }^{3}$ Study 3 was actually conducted after study 4 but is presented first for clarity of exposition.
}

been exposed to illicit alcohol consumption. Each student was asked to describe a drug- or alcohol-consumption situation in as much detail as possible. Most of these situations involved unsupervised parties on weekend nights, often involving 30 or more young people of both sexes. It is not surprising that marijuana consumption tended to be more covert and to occur in smaller groups, often a subgroup at the party, than did consumption of alcohol. It is interesting that most respondents reported that conformity pressures tend to be self-generated rather than the result of overt attempts of influence on the part of other individuals, although such attempts do occur. In other words, pressure to conform is most often generated internally as individuals think about the likely reactions of others to their drug- or alcohol-consumption decision. Respondents were also asked what kinds of thoughts and feelings they experienced when exposed to alcohol or drugs at these parties. A total of eight students reported thoughts involving either attributions about the behavior of the group (i.e., category 3 in Exhibit 1) or feelings of social anxiety related to the group's evaluation of their behavior (i.e., category 4 in Exhibit 1).

This open-ended question was followed by a direct question concerning causal search. In response to this question, nine respondents indicated that they were curious in these situations as to the reasons for the drug or alcohol users' behavior. Eight respondents indicated that the most likely explanation for drug or alcohol consumption in these settings involved fitting in with the group. It is interesting that the tendency to consume drugs or alcohol to fit in with the group was seen as dependent on an individual's personality. In particular, low self-esteem and low self-confidence were seen as contributing to susceptibility to peer pressure. Respondents indicated that they usually avoided going along with the group by relying on religious beliefs or parental guidance.

At the end of the interview, respondents were asked to read the scenario used in this research and to respond to some specific questions. In particular, nine respondents said that they had been in a situation like the one described in the scenario. In fact, one female said that she had been in a situation nearly identical to the marijuana scenario that very morning. Further, on a scale ranging from "not at all realistic" $(0)$ to "completely realistic" (10), respondents, on average, rated the realism of the scenario as 6.67 for marijuana and 7.47 for alcohol. Only three respondents rated the realism as 5 or below (ratings of 5, 5, and 3 for these respondents). These lower evaluations resulted from perceptions that members of the group would be unlikely to share expensive marijuana or that their friends would be unlikely to smoke marijuana. Finally, respondents were asked to estimate the percentage of students at their high school who had been in a situation similar to the one described in the scenario. These estimates 
averaged 52 percent for the marijuana scenario and 67 percent for the alcohol scenario.

From these depth interviews, we conclude that the scenarios used in this research are realistic and believable. This study also indicated the prevalence of peer pressures to conform in the consumption of drugs and alcohol among high school students. This observation is not surprising. However, it was interesting to note that our respondents felt that conformity pressures tended to be self-generated rather than overt, a perception that is consistent with Calder and Burnkrant's (1977) attributional conformity model. Still, it should be noted that these conclusions must be tempered by consideration of the nature of the students interviewed. The high school is in an upper-middle-class neighborhood. The students interviewed are all Caucasian and primarily female. Whether the conformity pressures experienced by young people of other races or socioeconomic statuses differ in nature or degree from those reported by our sample is not known.

\section{STUDY 4}

Study 4 was designed with two major objectives in mind-one conceptual in nature and the other related to measurement. First, Ross et al. (1976) have suggested that certain types of attributions (i.e., external explanations) may contribute more to dissent than others will. Thus, one objective of study 4 was to test this proposition, that is, that external explanations for the group's behavior are associated with stronger dissent than are internal explanations (Hypothesis 3). Second, the previous studies have provided some insight into the types of attributional thoughts that occur when young people are confronted with group pressures to use drugs and alcohol. However, other attribution research has suggested that measures of potential explanations for a group's substance abuse are more likely to be closely related to subsequent conformity or dissent if those measures are specific to the target behavior and stated in the words that would be used by the population under study (Elig and Frieze 1979). Thus, more descriptive research that summarizes thoughts in the adolescents' own words may be of value to policymakers whose chief concern is to create programs capable of strengthening resistance to group pressures. Therefore, in addition to tests of abstract attributional issues (i.e., internal vs. external locus of causality), several more situation-specific attribution measures, which themselves could be characterized as internal or external in nature, were included in study 4.

\section{Method}

Eighty-eight high school juniors and seniors, 51 females and 37 males, participated in the study in a classroom setting. Once again, the respondents were asked to project themselves in the role of a young person of- fered marijuana by three friends at a party. The scenario was identical to that used in study 2 , except for the substitution of marijuana for alcohol. The average student completed the entire procedure in about $25 \mathrm{~min}-$ utes. Debriefing was accomplished immediately following the collection of the survey instruments. Attention to the task was high, and all 88 questionnaires were usable and remarkably complete.

Respondents read the scenario at their own pace and then began the questionnaire. Students indicated the extent of their intentions to smoke marijuana by marking a point on the same 11-point scale used in the previously reported studies. Next, the internal versus external attribution dimension (locus) was assessed with a nine-point scale anchored by "completely internal" (1) and "completely external" (9; see Miller et al. 1981; Smith and Miller 1982) after instructions concerning the meaning of the endpoints of this continuum. Subjects were told that internal explanations relate to characteristics of the persons smoking marijuana, such as their personality, values, attitudes, and desires. External explanations were described as relating to characteristics of the situation facing the persons smoking marijuana, such as peer pressures, laws, or the social environment.

The target explanations used to construct the situation-specific attribution measures were derived from studies 1 and 2 and from a pretest $(n=32)$ in which undergraduate students were asked to list plausible explanations for the group's behavior in the marijuana scenario used in study 1 . The three most frequently mentioned internal and external explanations were then selected for use in study 4 . The three external attributions were as follows: "Your friends are smoking marijuana because they are concerned with looking 'cool' to others"; "Your friends feel peer pressure from other friends to smoke marijuana"; and "Your friends are smoking marijuana because they are concerned about 'fitting in' with other friends." The three internal explanations were: "Your friends are smoking marijuana because they don't care about damaging their health"; "Your friends are smoking marijuana because they don't care about getting in trouble with the law"; and "Your friends are smoking marijuana because they like to get 'high.'"

The strength of each of these specific attribution measures was assessed with nine-point scales anchored by extremely unlikely (1) and extremely likely (9). That is, respondents were asked to report the likelihood that the group's behavior resulted from each of the six specific causes: (1) peer pressure, (2) looking cool to impress others, (3) fitting in with friends, (4) not caring about damaging their health, (5) the desire to get high, and (6) not caring about getting in trouble with the law. Respondents were also asked to report the likely effect of each of these explanations on their conformity decision. For example, respondents were asked, "If the people in the group are smoking marijuana in order to look cool to impress their friends, would this make you 
TABLE 2

MEANS AND CORRELATIONS WITH CONFORMITY - STUDY 4

\begin{tabular}{|c|c|c|c|c|}
\hline & $\begin{array}{l}\text { Correlation with } \\
\text { conformity }\end{array}$ & $p$-Value & Mean & Standard deviation \\
\hline \multicolumn{5}{|l|}{ Variable: } \\
\hline Conformity & & $\ldots$ & 3.19 & 3.08 \\
\hline Locus of causality (locus) & -.306 & .01 & 5.15 & 2.21 \\
\hline \multicolumn{5}{|l|}{ Situation-specific attributions: } \\
\hline 1. Peer pressure (PEER) & -.394 & .001 & 5.93 & 2.39 \\
\hline 2. Look cool (COOL) & -.416 & .001 & 6.21 & 2.43 \\
\hline 3. Fit in (FITIN) & -.145 & .10 & 6.84 & 2.51 \\
\hline 4. No health concerns (HEALTH) & .215 & .05 & 3.88 & 2.31 \\
\hline 5. Get high (GETHIGH) & .332 & .001 & 7.60 & 1.81 \\
\hline 6. No fear of law (LAW) & .056 & NS & 4.19 & 2.65 \\
\hline \multicolumn{5}{|l|}{ Attribution effects on conformity: } \\
\hline 1. Effect of PEER & .092 & NS & 2.89 & 2.12 \\
\hline 2. Effect of $\mathrm{COOL}$ & .230 & .05 & 2.21 & 1.74 \\
\hline 3. Effect of FITIN & .220 & .05 & 2.46 & 1.77 \\
\hline 4. Effect of HEALTH & .576 & .001 & 2.08 & 1.74 \\
\hline 5. Effect of GETHIGH & .774 & .001 & 3.86 & 3.01 \\
\hline 6. Effect of LAW & .319 & .001 & 2.31 & 1.98 \\
\hline
\end{tabular}

NOTE.-Four types of scales were used and labeled as follows: conformity, no chance (1) to definitely (11); locus, completely internal (1) to completely external (9); situation-specific attributions, extremely unlikely (1) to extremely likely (9); and attribution effects, less likely (1) to more likely (9).

more likely or less likely to smoke marijuana yourself?" Similar likelihood estimates were obtained for each explanation on a nine-point scale anchored by "less likely" (1) and "more likely" (9).

\section{Mean Differences and Correlation Test Results}

The means and standard deviations for each scaled measure are reported in Table 2. Mean intentions to smoke marijuana were lower $(\bar{X}=3.19, \mathrm{SD}=3.08)$ than they were for the alcohol scenario (i.e., study 2 ), as would be expected. The mean for the key locus measure was 5.15 , almost exactly at the scale midpoint. Interestingly, getting high was seen as the most likely specific reason for the group's behavior $(\bar{X}=7.60)$, followed by the external explanations of fitting in $(\bar{X}=6.84)$ and being cool $(\bar{X}=6.21)$. None of the specific attributions were seen, on average, as being very likely to increase conformity. However, the effect of getting high $(\bar{X}$ $=3.86$ ) on intentions was viewed as somewhat stronger than the effects of the other explanations.

Pearson correlation coefficients were computed to assess the degree of association between the attribution measures and intentions to smoke marijuana. These correlations are reported in Table 2. Intentions were inversely related to the tendency to attribute the group's behavior to external factors $(r=-.31, p<.01)$. That is, the more external the respondents viewed the cause of the group's behavior to be, the lower were their reported intentions to join the group in smoking marijuana. This relationship was examined further by using respondents' locus scores to form a blocking factor. Re- spondents who scored below the mean were assigned to the internal locus group $(n=31)$, while those scoring above the mean were assigned to the external locus group $(n=36)$. Analysis of variance was then used to test for differences in mean intentions scores between these groups. The result supported the correlational analysis in that those making internal attributions reported stronger intentions to smoke marijuana ( $\bar{X}$ $=4.58)$ than did those who made external attributions $(\bar{X}=2.56, F(1,65)=7.20, p<.01)$.

\section{Specific Attribution Results}

The data from the situation-specific attribution measures reveal some very interesting patterns of association with intentions to smoke marijuana that are consistent with the locus-measure results described above. First, the strength of each attribution is significantly related to intentions, with the exception of getting in trouble with the law. Second, the external explanations of peer pressure, fitting in, and being cool are all negatively related to intentions. In other words, respondents who perceived external attributions to be more likely tended to report weaker intentions to smoke marijuana. Third, the explanations related to the internal reasons of not caring about one's health and especially of getting high were positively associated with intentions to smoke. ${ }^{4}$

\footnotetext{
${ }^{4} \mathrm{As}$ a check of our interpretation of the specific attribution measures as either internal or external in nature, we computed the correlations between the locus measure and each specific attribution measure. As expected, peer pressure, being cool, and fitting in were all significantly $(p<.05)$ and positively associated with locus scores $(r=.27, .21$,
} 
These results support the notion that attributions carry different implications for conformity and dissent. The relationships of being cool, peer pressure, and getting high $(r=-.42,-.39$, and .33 , respectively) to intentions were similar in magnitude but varied in direction. That is, the two external attributions were negatively associated with intentions while the internal attribution was positively associated with intentions.

One explanation for this pattern of results is that the respondents considered getting high a more likely reason for the group's behavior (and perhaps more desirable) than either of the two external reasons. Because we also asked respondents to report the likely effect of each of these attributions on their propensity to comply, evidence regarding this explanation was available in the data. In Table 2 , note that, on average, respondents thought that the effect of all six attributions would be to reduce compliance. However, in the case of getting high, this tendency was somewhat less pronounced (i.e., the mean was higher). The standard deviation for the measure of the effect of getting high was much higher as well, indicating that there was a much wider range of opinion regarding the viability of getting high as a reason for smoking the marijuana.

\section{Discussion and Limitations}

Although the attributions that we used in study 4 were carefully chosen after examining the importance and frequency of explanations identified in pretests and the exploratory studies, it is still possible that the external explanations we chose to study happened to carry more negative implications for group attractiveness than did the personal explanations that were studied. Our data do not permit a direct examination of this issue. Thus, our conclusions regarding the relationship between the locus of causality of attributions and conformity are limited to the six explanations that were studied. We can only speculate regarding the relationship, if any, between other attributions and conformity.

Also, no direct test of mediation is possible with our data. Nevertheless, partial correlations were computed in which the association between attribution strength and intentions to smoke marijuana was reassessed after accounting for the variance shared with group attractiveness. If group attractiveness is the sole mediator of the effects of attributions on conformity, then the partial correlations between each of the six attributions and intentions should be reduced to nonsignificance. The results of these analyses indicated some attenuation of

and .24 , respectively), a result that supports our expectation that these are primarily external attributions. The remaining correlations with locus were weaker (not concerned about health: $r=-.01$, NS; getting high: $r=-.16, p<.10$; and trouble with the law: $r=-.17$, $p<.10$ ) but still supportive of our interpretation that these attributions are internal, at least for getting high and getting in trouble with the law. the attribution and intentions relationship when group attractiveness is controlled for. However, for peer pressure and being cool, the partial correlations remained significant $(p<.01)$ and negative, while for health and getting high, the partial correlations remained significant and positive ( $p<.01$ and $p<.02$, respectively). Thus, our data suggest that group attractiveness does not account entirely for the observed negative relationship between the external attributions and intentions to smoke marijuana in this situation.

It should be stressed that our data are correlational and can be used to suggest, but not confirm, a causal role for attributions in conformity. Finally, similar to studies 1 and 2, this study made use of role-playing methods and private measures because of the sensitive nature of drug and alcohol consumption among high school students. One cannot assume with confidence that the results obtained are generalizable to other populations or other conformity situations.

\section{GENERAL DISCUSSION}

Perhaps the most noteworthy implication of this research concerns the association of attributional processing with resistance to group pressure. In general, conformity to group pressure was found to be reduced in the presence of attributional thinking concerning the group's behavior or reactions, as suggested by the work of Ross et al. (1976). This relationship was relatively robust. That is, it was obtained for both high school and college students and held whether the attributional information was provided by the experimenters (study 4) or generated by the subjects themselves (study 2). Thus, our data suggest that attributions about a peer group's deviant behavior may play an important role in the decision-making process of a potential dissenter. Still, as we discuss below, caution is advisable in the interpretation of our results.

In the following discussion, we focus on three major issues. ${ }^{5}$ First, although our results are generally consistent with expectations, the process underlying the conformity-inhibiting effects of attributional processing warrants further examination. Second, our data support the notion that the presence of attributional thinking is advantageous when young people are faced with conformity pressures. However, we are unable to address more subtle questions concerning numbers and types of attributions. Third, it is worth noting that current anti-substance abuse programs such as "Just Say No!" stress assertiveness but do not emphasize the types of causal reasoning examined in this research. However, it would be imprudent to recommend changes on the basis of these data alone. The reasons for our caution are addressed below. Finally, we discuss the limitations

\footnotetext{
${ }^{5} \mathrm{We}$ are indebted to anonymous reviewers for many of the insights discussed in this section.
} 
of our research in some detail and make suggestions for future research.

\section{Why Does Attributional Thinking Reduce Conformity?}

The explanation suggested by Ross et al. (1976) is that the availability of attributions to account for the group's behavior, in effect, provides excuses for the potential dissenter's refusal to go along. The dissenter need not conform because the group is subject to different situational contingencies (an external attribution) or the group values the consequences of its behavior differently than the dissenter does (an internal attribution). Dissent is further bolstered if the individual believes that the group also clearly perceives these differences and, therefore, could explain the individual's dissent satisfactorily. An alternative explanation for the inverse relationship observed between conformity and attributional thinking observed in this research relies on more of an informational social influence process. Internal attributions (e.g., liking to get high) may be considered "better" reasons for smoking marijuana or drinking alcohol than external attributions (e.g., pressure from others) and, thus, may be more likely to be internalized.

Further, attributions may affect conformity through an identification process. That is, attributions may carry quite different implications for the attractiveness of the peer group. As noted above, explanations that indicate that the group's behavior is based on members' personal conviction (e.g., they like getting high) may be viewed more favorably (or relatively less negatively) than those that suggest that the group is acting to please others (e.g., acting in response to peer pressure). Further, programs such as "Just Say No!" that portray conformity very negatively may have reduced the favorability of social facilitation reasons for deviant behavior in general, relative to personal reasons. Therefore, attributions may affect conformity through their implications for group attractiveness. Those explanations that are viewed unfavorably may reduce the attractiveness of the group and suppress conformity as well, relative to more favorable explanations that enhance group attractiveness.

\section{Effects of Multiple Attributions on Conformity}

We have argued that dissent is bolstered when plausible explanations for the group's deviant behavior become available (even just one). Thus, those making an attribution for the group's behavior were expected to conform less than those not making such an attribution. The data from study 2 supported this expectation. However, it is possible that being able to explain the group's behavior in more than one way is an advantage. That is, multiple explanations may provide additional support for dissent beyond that offered by a single explanation. This effect could result from several underlying processes. For example, having a set of plausible explanations may increase the likelihood that the group will understand the reasons behind the dissent and, therefore, withhold punishment or disapproval. Also, additional explanations may bolster dissent by reinforcing perceived differences between the contingencies facing the group and those facing the dissenter.

\section{Caution regarding Intervention Strategies}

This research has demonstrated that attributional processing is associated with reduced conformity in roleplaying conformity settings. However, it is also clear that more than one psychological mechanism may underlie the effects observed. It would be imprudent to advocate the development and implementation of intervention programs designed to encourage attributional processing until a better understanding of the implications for conformity of different types of attributions is obtained. Our data support the superiority of certain types of external explanations as a means to bolster dissent. However, does this advantage disappear if an external attribution is made that also happens to carry favorable implications for the attractiveness of the group? Likewise, it would seem desirable to encourage young people to make attributions for the group's substance abuse that are damaging to the attractiveness of the group. But, if some of these groupdisparaging attributions are internal in nature (e.g., the group does not care about health damage), would their effectiveness be diminished? In short, the results obtained in this research regarding the importance of attributional processing as a means of reducing conformity are interesting from both theoretical and substantive perspectives. However, much work remains to be done before intervention programs can be confidently prescribed.

\section{Future Research}

The current research raises some intriguing questions regarding the effects of providing subjects with information regarding peer groups' behavior, especially information pertaining to external reasons for that behavior. If, as suggested by our research, internal and external explanations for deviant behavior carry different implications for conformity, would it be wise to encourage attributional reasoning on the part of pressure-susceptible populations of young people? Clearly, additional research is needed if we are, first, to understand these effects more fully and, second, to prescribe intervention strategies with some degree of confidence. One approach to meeting the first objective would be to manipulate the propensity to engage in attributional processing directly in some way. Hastie's (1984) model of attributional instigators would be a useful starting 
point. For example, instructions to conduct attributional reasoning could be given to one group but not to another, with the expectation that the attribution group would report lower conformity intentions than the control group would. The problem with this approach is that, even in the absence of directed attributional processing, our research has shown that attributional processing occurs with considerable frequency. Thus, it may be necessary to find means by which to inhibit attributional thinking in one condition while requiring it in another.

Another approach to the problem would be to manipulate the nature of subjects' attributional thinking. For example, groups of subjects could be given instructions regarding either external or internal reasons for the consumption of illicit substances. Subjects would then be asked to search for external (internal) reasons for the group's behavior after reading the scenario. A control group would receive no training or instruction. If attributional thinking in general bolsters dissent, then both experimental groups would be expected to report lower conformity intentions than the control group would. Further, if external attributions contribute most powerfully to dissent, then the lowest conformity intentions should be observed in the condition in which subjects are instructed to think about external reasons for the group's behavior. Also, if group attractiveness were measured, a test of causal mediation would be possible with this experimental design.

\section{CONCLUSION}

In summary, this research has provided evidence in support of the following propositions regarding the role of attributions and attributional processing in resisting group pressures to use illicit drugs and alcohol. First, young people engage in causal reasoning when exposed to drug- and alcohol-related peer pressures (studies 13 ). Second, the presence of attributional thinking is associated with a reduction in conformity (study 2 ). Third, external attributions for a peer group's behavior are associated with stronger dissent than are internal attributions, regardless of whether the attributions are measured at the abstract or situation-specific level (study 4).

Our research supports the presence of attributional processing in response to peer pressure to use drugs and alcohol and suggests that attributional processing may be a mechanism for reducing conformity. From an intervention perspective, it is important to be able to say with confidence that certain types of attributions should be encouraged while others should be avoided. Clearly, there remains much work to be done in this area before such a confident assessment can be made. The payoffs, in terms of enhancing our understanding of conformity processes and the development of effective measures to reduce conformity-related consumption of drugs and alcohol, are potentially very valuable. We are commit- ted to doing this work, and we hope that our research will encourage others to contribute as well. Although the present research represents a modest start toward the development of the desired level of understanding, at least a start has been made.

\section{[Received November 1990. Revised October 1991.]}

\section{REFERENCES}

Asch, Solomon (1951), "Effects of Group Pressure upon the Modification and Distortion of Judgments," in Readings in Social Psychology, ed. Eleanor E. Maccoby et al., New York: Holt, Rinehart \& Winston, 174-182.

Brook, Judith S., Martin Whiteman, and Ann Scovell Gordon (1983), "Stages of Drug Use in Adolescence: Personality, Peer, and Family Correlates," Developmental Psychology, 19 (2), 269-277.

Brown, B. Bradford, Donna Rae Clasen, and Sue Ann Eicher (1986), "Perceptions of Peer Pressure Conformity, Dispositions, and Self-reported Behavior among Adolescents," Developmental Psychology, 22 (4), 521-530.

Calder, Bobby J. and Robert E. Burnkrant (1977), "Interpersonal Influences on Consumer Behavior: An Attribution Theory Approach," Journal of Consumer Research, 4 (June), 29-38.

Elig, Timothy W. and Irene Hanson Frieze (1979), "Measuring Causal Attributions for Success and Failure," Journal of Personality and Social Psychology, 37 (4), 621 634.

Folkes, Valerie S. (1984), "Consumer Reactions to Product Failure: An Attributional Approach," Journal of Consumer Research, 10 (March), 398-409.

(1988), "Recent Attribution Research in Consumer Behavior: A Review and New Directions," Journal of Consumer Research, 14 (March), 548-565.

Halebsky, Mark A. (1987), “Adolescent Alcohol and Substance Abuse: Parent and Peer Effects," Adolescence, 22 (Winter), 961-967.

Hastie, Reid (1984), "Causes and Effects of Causal Attribution," Journal of Personality and Social Psychology, 46 (1), 44-56.

Heider, Fritz (1958), The Psychology of Interpersonal Relations, New York: Wiley.

Huba, G. J. and Peter M. Bentler (1980), "The Role of Peer and Adult Models for Drug Taking at Different Stages in Adolescence," Journal of Youth and Adolescence, 9 (5), 449-465.

Jessor, R. and S. Jessor (1977), Problem Behavior and Psychosocial Development, New York: Academic Press.

Kandel, Denise B., Ronald C. Kessler, and Rebecca Z. Margulies (1978), "Antecedents of Adolescent Initiation into Stages of Drug Use: A Developmental Analysis," Journal of Youth and Adolescence, 7 (1), 13-40.

Kaplan, Howard B., Steven S. Martin, and Cynthia Robbins (1985), "Toward an Explanation of Increased Involvement in Illicit Drug Use: Application of a General Theory of Deviant Behavior," Research in Community and Mental Health, 5, 205-252.

Marcos, Anastasios C., Stephen J. Bahr, and Richard E. Johnson (1986), "Test of a Bonding/Association Theory of Adolescent Drug Use," Social Forces, 65 (September), 135-161. 
Miller, Frederick D., Eliot R. Smith, and James Uleman (1981), "Measurement and Interpretation of Situational and Dispositional Attributions," Journal of Experimental Social Psychology, 17, 80-95.

Mizerski, Richard W., Linda L. Golden, and Jerome B. Kernan (1979), "The Attribution Process in Consumer Decision Making," Journal of Consumer Research, 6 (September), 123-140.

Pryor, John and Mitchel Kriss (1977), "The Cognitive Dynamics of Salience in the Attribution Process," Journal of Personality and Social Psychology, 35, 49-55.

Ross, Lee, Gunter Bierbrauer, and Susan Hoffman (1976), "The Role of Attribution Processes in Conformity and Dissent," American Psychologist, 31 (February), 148157.

Smith, Eliot and Frederick D. Miller (1982), "Latent-Variable Models of Attributional Measurement," Personality and Social Psychology Bulletin, 8 (2), 221-225.

Stein, Judith A., Michael D. Newcomb, and Peter D. Bentler (1987), “An 8-Year Study of Multiple Influences on Drug
Use and Drug Use Consequences," Journal of Personality and Social Psychology, 53 (6), 1094-1105.

Weiner, Bernard (1985), "Spontaneous Causal Thinking," Psychological Bulletin, 97 (1), 74-84.

Winfree, L. Thomas (1985), "Peers, Parents, and Adolescent Drug Use in a Rural Community: A Two-Wave Panel Study," Journal of Youth and Adolescence, 14 (60), 499512.

Wolfe, Raymond N., Richard D. Lennox, and Brian L. Cutler (1986), "Getting Along and Getting Ahead: Empirical Support for a Theory of Protective and Acquisitive SelfPresentation," Journal of Personality and Social Psychology, 50 (2), 356-361.

Wong, Paul T. P. and Bernard Weiner (1981), "When People Ask 'Why' Questions and the Heuristics of Attributional Search," Journal of Personality and Social Psychology, 40 (4), 650-663.

Wright, Peter (1975), "Factors Affecting Cognitive Resistance to Advertising," Journal of Consumer Research, 2 (June), $1-9$. 